University of Nebraska - Lincoln

DigitalCommons@University of Nebraska - Lincoln

Diana Pilson Publications

Papers in the Biological Sciences

2002

\title{
Compensation for Herbivory in Wild Sunflower: Response to Simulated Damage by the Head- Clipping Weevil
}

Diana Pilson

University of Nebraska-Lincoln, dpilson1@unl.edu

Karin L. Decker

University of Nebraska-Lincoln

Follow this and additional works at: http://digitalcommons.unl.edu/bioscipilson

Part of the Botany Commons, Genetics Commons, Other Ecology and Evolutionary Biology Commons, Other Plant Sciences Commons, Plant Biology Commons, and the Weed Science Commons

Pilson, Diana and Decker, Karin L., "Compensation for Herbivory in Wild Sunflower: Response to Simulated Damage by the HeadClipping Weevil" (2002). Diana Pilson Publications. 2.

http://digitalcommons.unl.edu/bioscipilson/2

This Article is brought to you for free and open access by the Papers in the Biological Sciences at DigitalCommons@University of Nebraska - Lincoln. It has been accepted for inclusion in Diana Pilson Publications by an authorized administrator of DigitalCommons@University of Nebraska - Lincoln. 


\title{
COMPENSATION FOR HERBIVORY IN WILD SUNFLOWER: RESPONSE TO SIMULATED DAMAGE BY THE HEAD-CLIPPING WEEVIL
}

\author{
Diana Pilson and Karin L. Decker ${ }^{1}$ \\ School of Biological Sciences, 348 Manter Hall, University of Nebraska, Lincoln, Nebraska 68588-0118 USA
}

\begin{abstract}
Herbivore damage is generally detrimental to plant fitness, and the evolutionary response of plant populations to damage can involve either increased resistance or increased tolerance. While characters that contribute to resistance, such as secondary chemicals and trichomes, are relatively well understood, characters that contribute to a plant's ability to tolerate damage have received much less attention. Using Helianthus annuus (wild sunflower) and simulated damage of Haplorhynchites aeneus (head-clipping weevil) as a model system, we examined morphological characters and developmental processes that contribute to compensatory ability. We performed a factorial experiment that included three levels of damage (none, the first two, or the first four inflorescences were clipped with scissors) and eight sires each mated to four dams. We found that plants compensated fully for simulated head-clipper damage and that there was no variation among plant families in compensatory ability: seed production and mean seed mass did not vary among treatments, and sire $\times$ treatment interactions were not significant. Plants used four mechanisms to compensate for damage: (1) Clipped plants produced significantly more inflorescences than unclipped plants. Plants produced these additional inflorescences on higher order branches at the end of the flowering season. (2) Clipped plants filled significantly more seeds in their remaining heads than did unclipped plants. (3) Clipped plants, because they effectively flowered later than unclipped plants, were less susceptible to damage by seedfeeding herbivores other than Haplorhynchites. (4) In later heads, seed size was greater on clipped plants, which allowed mean seed size to be maintained in clipped plants. Although there was genetic variation among the families used in this experiment for most of the characters associated with compensation for damage (seed number, mean seed size, mean flowering date, length of the flowering period, and branching morphology), in analyses of these characters, no sire $\times$ treatment interactions were significant indicating that all of the families relied on similar mechanisms to compensate for damage.
\end{abstract}

Key words: Haplorhynchites aeneus; Helianthus annuus; herbivory; mechanisms of compensation, mechanisms of tolerance; plant-herbivore interactions.

\section{INTRODUCTION}

Herbivore damage is generally detrimental to plant fitness (for review see, e.g., Crawley 1983, 1993, Marquis 1992), and it is now recognized that plant populations may respond to this damage by evolving either resistance or tolerance. Characters that reduce the amount of damage experienced by plants, including secondary chemicals, trichomes, and phenological patterns that allow escape from damage, are said to confer resistance. Alternatively, plants may evolve mechanisms that allow them to tolerate damage with relatively little loss in fitness (Stowe et al. 2000, Tiffin 2000). Evolutionary ecologists have only recently begun to focus on tolerance as an evolved response to damage, and mechanisms of tolerance are very poorly understood.

Most studies of the evolution of tolerance have focused only on operationally defined tolerance and have

Manuscript received 10 October 2001; revised 5 April 2002; accepted 8 April 2002.

${ }^{1}$ Present address: 1010 Stein St., Lafayette, Colorado 80026 USA. not investigated underlying mechanisms (Simms and Triplett 1994, Mauricio et al. 1997, Agrawal et al. 1999, Tiffin and Rausher 1999, Foroni and Nunez-Farfan 2000, Hochwender et al. 2000, Pilson 2000b; but see Fineblum and Rausher 1995, Juenger and Bergelson 2000). Although methods vary among studies, the tolerance of a half- or full-sib family (or other set of related individuals) is generally defined as the fitness of damaged plants relative to the fitness of undamaged plants. For example, in cases in which damage has a nonlinear effect on fitness, tolerance is best described as the area under the curve defined by the regression of fitness on damage and damage squared (Pilson $2000 b$ ). While operational definitions clearly integrate all contributing characters into a single measure of tolerance, they provide no indication of what those contributing characters might be. Furthermore, multiple characters (including perhaps the activation of dormant meristems or changes in photosynthetic rates) may simultaneously contribute to tolerance, as well as individually contribute to other fitness enhancing functions in the plant. Because each character that contributes to tolerance may face different evolutionary constraints, 
examining constraints on operationally defined tolerance may be very difficult. Thus, understanding the evolution of tolerance, and constraints on the simultaneous evolution of resistance and tolerance (e.g., Mauricio et al. 1997, Tiffin and Rausher 1999, Pilson $2000 \mathrm{~b}$ ) will require elucidation of characters conferring the ability to tolerate herbivory (Maurico 2000, Tiffin 2000).

A number of mechanisms have been proposed to increase plant compensatory ability (for review, see Strauss and Agrawal 1999, Kotanen and Rosenthal 2000, Tiffin 2000). Clearly the best explored of these mechanisms is the activation of dormant meristems. In several species with strong apical dominance, grazing damage to elongating shoots breaks apical dominance, which, in turn, allows branching and confers tolerance (Paige and Whitham 1987, Maschinski and Whitham 1989, Prins and Verkaar 1989, Doak 1991, Tuomi et al. 1994, Bergelson et al. 1996, Juenger and Bergelson 1997, Lennartsson et al. 1998, Huhta et al. 2000b). By contrast, little work has focused on activation of meristems in species without such dramatic apical dominance.

Another potential mechanism of tolerance is the utilization of stored resources. For example, van der Meijden et al. (1988) found that, among five biennial species, regrowth following defoliation was greatest in species with larger root:shoot ratios. However, it would seem that stored resources cannot be solely responsible for compensatory ability because presumably those resources would have been used for some fitness enhancing function regardless of damage. Instead, it is possible that the pattern of resource allocation (e.g., Hochwender et al. 2000) or the timing of damage relative to the allocation of resources could affect compensatory ability. In addition, the specific pattern of resource allocation might differ in damaged and undamaged plants. For example, in a large-seeded species with high tolerance of damage to seedlings, resources stored in cotyledons are allocated immediately to regrowth in damaged seedlings, but to plant growth only over several months in undamaged plants (Dalling and Harms 1999). Similarly, resources that would have been used to fill seeds in a damaged inflorescence might instead be used to fill additional seeds in remaining inflorescences, and genetic variation in tolerance could be generated by genotypes that differ in the efficiency of their reallocation patterns.

Finally, herbivore damage frequently changes phenological patterns in plants. Most obviously, defoliation or meristem removal generally delays plant development (Harnett and Abrahamson 1979, Marquis 1988, Juenger and Bergelson 1997, Lennartsson et al. 1998, Meyer 1998). Variation among genotypes in the timing of developmental events (Juenger and Bergelson 2000), or in the phenological response to damage could affect compensatory ability. In addition, herbivore-in- duced changes in the timing of flowering may affect susceptibility to other herbivores (Pilson 2000a).

In this manuscript, we report the results of an experiment designed to elucidate mechanisms of tolerance of damage by the head-clipping weevil, Haplorhynchites aeneus, in wild sunflower, Helianthus annuus. By measuring several morphological and phenological characters in eight full-sib Helianthus families that had been subjected to varying levels of simulated Haplorhynchites damage, we are able to quantify compensatory ability, as well characters allowing plants to compensate for damage.

\section{EXPERIMENTAL ORGANISMS}

Helianthus annuus L. (Asteraceae), wild sunflower, is a weedy annual plant native to North America (Heiser et al. 1969). Sunflower is typically found in disturbed areas, and populations can range from just a few to several thousand plants (D. Pilson and K. Decker, personal observation). The current study took place at the University of Nebraska's Cedar Point Biological Station, where sunflower is abundant. At Cedar Point, located $\sim 9$ miles $(\sim 14.5 \mathrm{~km})$ northeast of Ogallala, Nebraska, USA and just to the south of Lake Ogallala, rainfall averages $47.5 \mathrm{~cm}$ annually and the soil is relatively sandy. Seedlings emerge from late April through most of May and mean plant height is $\sim 1.5$ $m$ (D. Pilson, personal observation). The number of inflorescences per plant averages between 10 and 18, depending on the year (Pilson 2000a; D. Pilson, unpublished data). The pattern of meristem commitment to inflorescences is quite regular: on undamaged plants the first inflorescence is always derived from the apical meristem, and the second from the secondary meristem in the leaf axil immediately below the apical meristem. Additional inflorescences are derived from meristems further down the plant, but lower meristems are more likely to differentiate vegetatively and then produce an inflorescence on a secondary meristem at the end of a branch. Later inflorescences may also be derived from tertiary and quaternary meristems. Plant size and morphology are very plastic and depend strongly on degree of crowding and water availability (D. Pilson, personal observation). In addition, our study population contains genetic variation for inflorescence number (D. Pilson, unpublished data), flowering phenology (Pilson $2000 a$ ), and patterns of meristem commitment (D. Pilson, unpublished data).

A large number of specialized herbivores feed on sunflower and the head-clipping weevil, Haplorhynchites aeneus Boheman (Curculionidae; Hamilton 1973), which is the focus of the experimental manipulations reported here, is among the most damaging. Female head-clipping weevils make a series of punctures girdling the peduncle, then move to the disc where they oviposit. Heads fall to the ground where the larvae feed on floret material. This damage can be easily simulated by clipping heads with scissors. Clipping gen- 
erally takes place within a few days of the time that the first florets on an inflorescence shed pollen, although early in the season, when open inflorescences are not abundant, buds may be clipped (D. Pilson and K. Decker, personal observation). Depending on the year, the mean percentage of heads per plant clipped by Haplorhynchites varies from $\sim 3$ to $15 \%$, and the mean number of heads per plant clipped varies from $\sim 0.5$ to 2.0 . Individual plants may lose $100 \%$ of their heads, and as many as 12 heads may be clipped on a single plant (Pilson 2000a; D. Pilson, unpublished data). Our study population contains genetic variation for resistance to Haplorhynchites, although this variation is completely accounted for by variation in flowering phenology (Pilson 2000a). Damage by Haplorhynchites is much more severe early in the flowering season, and early-flowering families are much more susceptible to damage by this herbivore than are laterflowering families.

In addition to Haplorhynchites, there are seven additional common herbivores that feed on head tissue or developing achenes (hereafter seeds) at Cedar Point. These are the moths Plagiomimicus spumosum Grote (Noctuidae), Cochylis hospes Walsingham (Cochylidae), and Isophrictis similiella Chambers (Gelechiidae); the red sunflower-seed weevil Smicronyx fulvus LeConte (Curculionidae), and the gray sunflower-seed weevil S. sordidus LeConte; the sunflower-seed midge, Neolasioptera helianthi Felt (Diptera: Cecidomyidae); and the sunflower-receptacle maggot Gymnocarena diffusa Snow (Diptera: Tephrididae). We can distinguish damage by each of these herbivores, and in this way we can quantify the amount of damage by each herbivore in each head. Detailed descriptions of damage by these herbivores can be found in Kreitner and Rogers (1981), Rogers et al. (1986), Underhill et al. (1987), Rogers (1988), Berglund (1994), Charlet et al. (1992, 1997), Pilson (2000a), and Pilson et al. (unpublished manuscript).

\section{Experimental Methods}

\section{Field methods}

In order to determine which plant characters or developmental processes allow sunflower to compensate for damage by Haplorhynchites, we performed a factorial experiment that included three levels of simulated Haplorhynchites damage and eight sires each mated to four dams. Haplorhynchites damage was manipulated by cutting with scissors either no heads on a plant, the first two heads produced by a plant, or the first four heads produced by a plant (to create the 0-cut, 2-cut, and 4-cut treatments). These treatments removed $\sim 15 \%$ and $\sim 30 \%$ of heads in the 2 -cut and 4 -cut treatments, respectively. Thus, the range of artificial damage in this experiment fell within, but towards the high end, of damage typically seen in natural populations. The earliest heads produced by plants were clipped to mimic the natural phenology of damage by this herbivore (Pilson 2000a), and these heads were clipped just as their first florets shed pollen, mimicking the behavior of Haplorhynchites. Natural damage was kept to a minimum by killing by hand all Haplorhynchites found in the experimental field.

The 32 full-sib families (eight sires each mated to four dams) we used in this experiment were chosen from a larger quantitative genetic design used in a previous experiment (Pilson 2000a) specifically because the sires showed extreme (and significantly different) values for characters we hypothesized might contribute to tolerance of damage by Haplorhynchites. Two of the sires were among the earliest flowering families and two were among the latest flowering. Similarly, in two of the sires, a low percentage of total leaf area was derived from leaves on branches, while in two of the sires a significantly larger percentage of total leaf area was derived from leaves on branches, indicating different patterns of meristem commitment. These families can be thought of as "skinny" and "bushy," respectively. Two seeds from each treatment, sire, and dam nested within sire combination were planted into each of two spatial blocks for a total of 384 plants in the experiment (three treatments $\times$ eight sires $\times$ four dams $($ sire $) \times$ two spatial blocks $\times$ two replicates $=$ 384 plants).

Seeds were germinated in the laboratory, sown into flats that were immediately placed outside, and transplanted into the field on 11 May 1997, when seedlings had reached the two-true-leaf stage. Seedlings that disappeared in the first $3 \mathrm{wk}$ following transplanting were replaced. Six of the 384 plants either died before flowering or did not flower and are not included in analyses presented here.

The earliest flowering plant opened its first inflorescence on 14 July and treatments were applied to each plant as inflorescences were produced. The date that each clipped and unclipped inflorescence opened its first florets and its position on the plant were noted. Each unclipped inflorescence was tagged and later collected. As seeds matured, inflorescences were collected individually into paper bags. Each collected head was later censused for damage by each of the seven herbivores that commonly feed on developing seeds and head tissue at Cedar Point and the number of viable seeds was counted. We used the number of viable seeds produced by each plant as an estimate of its maternal fitness. In addition, seeds produced by heads in a particular numerical sequence (i.e., seeds produced by the first and second heads, third and fourth heads, and so on) were summed for some analyses.

Herbivore damage to developing seeds was quantified as follows. For Isophrictis, C. hospes, S. sordidus, S. fulvus, and Neolasioptera, each head was categorized as either no seeds damaged, 1-30 seeds damaged, or $>30$ seeds damaged. These categorical estimates were converted to seed number estimates using a separate 
data set in which the actual number of seeds damaged by each of these herbivores was counted. Plagiomimicus and Gymnocarena were categorized as present or absent in each head. From Pilson (2000a) and Pilson et al. (unpublished manuscript), we know that when Plagiomimicus is present seed production is reduced by half; thus, we assumed that Plagiomimicus ate the same number of seeds as were viable in that head. From inspection and from the literature (Charlet et al. 1992), we estimate that when Gymnocarena is present it disrupts the development of approximately five seeds. In these ways, we were able to estimate the number of seeds eaten by each of the seven herbivores on each collected head. Damage estimates for each head were summed over all heads on a plant for some analyses, and over subsets of heads on a plant produced in a particular numerical sequence (as described for viable seed production) for others.

In addition, the viable seeds produced by each head were weighed. From these data we calculated total seed mass, the mean mass of all viable seeds, and the mean mass of seeds produced by heads in a particular numerical sequence (as described above) for each plant.

Finally, for each plant we quantified a number of phenological and morphological characters that we hypothesized might contribute to the ability to compensate for damage by Haplorhynchites. Phenological characters included the number of inflorescences produced by each plant, the day each plant opened its first inflorescence, the mean flowering date for each plant, and the length of the flowering period. The day the earliest flowering plant opened its first inflorescence was considered day 1 , and the flowering dates of all other inflorescences in the experimental population were assigned relative to day 1 .

To quantify branching morphology, we created an index we call "bushy," which is a mean of the branch position of all inflorescences on a plant. Specifically, inflorescences originating from a meristem on the main stem were considered primary, inflorescences originating from a primary branch were considered secondary, inflorescences originating from a secondary branch were considered tertiary, and so on.

\section{Statistical analyses}

To test the hypotheses that the clipping treatment affected seed production and that sires differed in their ability to compensate for Haplorhynchites damage we performed an ANOVA (using PROC GLM in SAS [1990]) which included block, treatment, sire, and dam nested within sire as main effects, as well as all of the two-way interactions between these factors. In this and in all similar analyses described below, none of the three-way interactions were significant and they were dropped from the analyses presented here. Because we selected the families used in this experiment based on characters we thought might be important for compensatory ability, we treated sire and dam within sire as fixed effects; thus, we employed a completely fixed effects model. Seed production was square-root transformed before analysis to improve normality. In this analysis of seed production, a significant treatment effect would indicate that, averaged over all sires in the population, the clipping treatment(s) decreased (or increased) seed production, and a significant sire $\times$ treatment interaction would indicate that some sires are more able to compensate for damage than others.

It is possible that plants compensate for clipping damage by increasing seed size rather than replacing lost seeds. To test this hypothesis, we performed ANOVAs of total seed mass and mean seed mass similar to the analysis of seed number described above. Total seed mass was square-root transformed before analysis to improve normality. Mean seed mass was extremely non-normal and could not be transformed to meet the assumptions of ANOVA. For this reason, we used PROC GLM (SAS 1990) to perform a nonparametric ANOVA on ranked data (analogous to a Kruskal-Wallis test for one-way ANOVA).

To determine if the clipping treatment affected any of the phenological or morphological characters described above, or if changes in any of these characters due to treatment varied among families, we analyzed these characters in separate ANOVAs similar to the analysis of seed production. Inflorescence number was square-root transformed before analysis to improve normality. The length of the flowering period and bushy, our index of branching morphology, were nearnormally distributed without transformation. To determine if the number of seeds eaten by herbivores other than Haplorhynchites differed among treatments, sires, or treatment $\times$ sire combinations we performed an ANOVA in which the number of seeds eaten by all herbivores feeding on the heads or developing seeds was the response. The number of seeds eaten was squareroot transformed before analysis to improve normality.

To determine if the timing of seed production or herbivore damage varied among plants in different treatments, we performed separate ANOVAs on seed production and herbivore damage in the third and fourth, fifth and sixth, seventh and eighth, ninth and tenth, and eleventh and higher heads produced by each plant. Seed production and herbivore damage in the first and second heads was not analyzed by ANOVA because only plants in the 0 -cut treatment had heads one and two. Similarly, analyses of the third and fourth heads only included plants in the 0 -cut and 2-cut treatments because the first four heads had been clipped from the 4-cut plants. (For the same reason (i.e., the data set would have included missing cells), these data were not analyzed by repeated-measures ANOVA.) Seeds produced in heads eleven and higher and all of the seeds-eaten variables were square-root transformed to improve normality; other variables were near-normally distributed without transformation. Significance levels for the five separate ANOVAs (on pairs of heads) 
TABLE 1. ANOVAs of seed production, total seed mass, and mean seed mass.

\begin{tabular}{|c|c|c|c|c|c|c|c|c|c|c|}
\hline \multirow[b]{2}{*}{ Source } & \multirow[b]{2}{*}{ df } & \multicolumn{3}{|c|}{ Seed production } & \multicolumn{3}{|c|}{ Total seed mass } & \multicolumn{3}{|c|}{ Mean seed mass } \\
\hline & & ss & $F$ & $P$ & SS & $F$ & $P$ & SS & $F$ & $P$ \\
\hline Block & 1 & 725.02 & 6.15 & 0.0138 & 2.13 & 2.97 & 0.0863 & 75.46 & 0.01 & 0.9316 \\
\hline Clipping treatment & 2 & 562.00 & 2.38 & 0.0944 & 1.76 & 1.23 & 0.2949 & 31366.35 & 1.53 & 0.2178 \\
\hline Sire & 7 & 2021.11 & 2.45 & 0.0192 & 10.42 & 2.08 & 0.0466 & 163610.53 & 2.29 & 0.0285 \\
\hline Dam(Sire) & 24 & 5917.75 & 2.09 & 0.0028 & 34.54 & 2.01 & 0.0046 & 688860.01 & 2.81 & 0.0001 \\
\hline Block $\times$ Clip & 2 & 467.55 & 1.98 & 0.1400 & 1.83 & 1.28 & 0.2800 & 6069.97 & 0.30 & 0.7434 \\
\hline Block $\times$ Sire & 7 & 1097.18 & 1.33 & 0.2370 & 9.26 & 1.85 & 0.0794 & 60749.09 & 0.85 & 0.5479 \\
\hline Block $\times$ Dam $($ Sire $)$ & 24 & 2486.25 & 0.88 & 0.6320 & 17.84 & 1.04 & 0.4188 & 173922.89 & 0.71 & 0.8409 \\
\hline Sire $\times$ Clip & 14 & 931.60 & 0.56 & 0.8913 & 9.55 & 0.95 & 0.5036 & 114776.79 & 0.80 & 0.6668 \\
\hline $\operatorname{Dam}($ Sire $) \times$ Clip & 48 & 5243.89 & 0.96 & 0.5560 & 38.31 & 1.11 & 0.2959 & 509632.85 & 1.04 & 0.4133 \\
\hline Error & $\dagger$ & 29252.20 & & & 171.97 & & & 2453605.54 & & \\
\hline
\end{tabular}

Note: Type III SS are reported.

$\dagger$ Error df are 377 for seed production and 369 for total seed mass and mean seed mass.

and the three pair-wise comparisons between treatments (within each ANOVA), were adjusted using the Bonferroni correction.

Finally, to determine if any differences in seed mass depended on the phenology of inflorescence production, we examined among treatment variation in mean seed mass in the third and fourth, fifth and sixth, seventh and eighth, ninth and tenth, and eleventh and higher heads, as described for seed production and herbivore damage. Mean seed masses were far from normally distributed and, for this reason, we performed nonparametric ANOVAs on ranked data (as described above). Because plants with few heads had missing mean seed mass data for later heads, sample sizes were sometimes too small to include the two-way interactions in the analyses. For this reason these analyses of mean seed mass included only main effects. Significance levels were adjusted for multiple tests and multiple comparisons as described above for seed number and seeds eaten.

\section{RESULTS}

The number of seeds produced did not differ among plants in the three treatments, indicating that plants fully compensated for simulated damage by the headclipping weevil (Table 1, Fig. 1). In addition, although the sires used in this experiment did vary in seed production, there was no genetic variation for the ability to compensate for damage (nonsignificant sire $\times$ clipping treatment interaction; Table 1, Fig. 2). Likewise, neither total seed mass nor mean seed mass varied among treatments (Table 1), indicating that maintaining seed number when damaged did not come at the expense of reduced seed size. Again, while sires varied for both total and mean seed mass, the sire $\times$ clipping treatment interactions were not significant, indicating that the treatments affected seed size in similarly in all sires.

We next performed a series of analyses to determine what characters or developmental processes allowed plants to compensate for damage. Plants in the 2-cut and 4-cut treatments produced significantly more inflorescences than did plants in the 0 -cut treatment (Table 2, Fig. 3a): 0-cut plants produced a mean of 11.0 inflorescences, while 2-cut and 4-cut plants produced a mean of 13.3 and 13.6 inflorescences, respectively. Plants produced these additional inflorescences by significantly increasing the length of the flowering period from $20.6 \mathrm{~d}$ in the 0 -cut treatment to $24.1 \mathrm{~d}$ in the 2 cut treatment and $27.6 \mathrm{~d}$ in the 4-cut treatment (Table 2, Fig. 3b). In addition, these additional inflorescences were produced on higher order branches, so that plants

TABLE 2. ANOVAs of number of inflorescences, length of the flowering period, and bushy (an index of branching morphology).

\begin{tabular}{|c|c|c|c|c|c|c|c|c|c|c|}
\hline \multirow[b]{2}{*}{ Source } & \multirow[b]{2}{*}{ df } & \multicolumn{3}{|c|}{ Number of inflorescences } & \multicolumn{3}{|c|}{ Length of flowering period } & \multicolumn{3}{|c|}{ Bushy } \\
\hline & & ss & $F$ & $P$ & SS & $F$ & $P$ & SS & $F$ & $P$ \\
\hline Block & 1 & 7.54 & 13.73 & 0.0003 & 355.06 & 5.51 & 0.0197 & 1.12 & 17.78 & 0.0001 \\
\hline Clipping treatment & 2 & 11.08 & 10.08 & 0.0001 & 3032.50 & 23.53 & 0.0001 & 1.01 & 8.06 & 0.0004 \\
\hline Sire & 7 & 7.25 & 1.88 & 0.0726 & 2697.63 & 5.98 & 0.0001 & 2.04 & 4.63 & 0.0001 \\
\hline $\operatorname{Dam}($ Sire $)$ & 24 & 38.35 & 2.91 & 0.0001 & 4292.08 & 2.78 & 0.0001 & 2.33 & 1.55 & 0.0533 \\
\hline Block $\times$ Clip & 2 & 0.06 & 0.05 & 0.9484 & 347.09 & 2.69 & 0.0697 & 0.02 & 0.13 & 0.8772 \\
\hline Block $\times$ Sire & 7 & 2.43 & 0.63 & 0.7287 & 645.60 & 1.43 & 0.1932 & 0.19 & 0.45 & 0.8714 \\
\hline Block $\times$ Dam (Sire) & 24 & 11.77 & 0.89 & 0.6129 & 1278.82 & 0.83 & 0.7011 & 1.82 & 1.21 & 0.2333 \\
\hline Sire $\times$ Clip & 14 & 7.47 & 0.97 & 0.4842 & 1046.49 & 1.16 & 0.3070 & 1.38 & 1.57 & 0.0877 \\
\hline $\operatorname{Dam}($ Sire $) \times$ Clip & 48 & 30.48 & 1.16 & 0.2396 & 3011.93 & 0.97 & 0.5274 & 3.99 & 1.33 & 0.0884 \\
\hline Error & 377 & 136.29 & & & 15982.46 & & & 15.56 & & \\
\hline
\end{tabular}

Note: Type III SS are reported. 


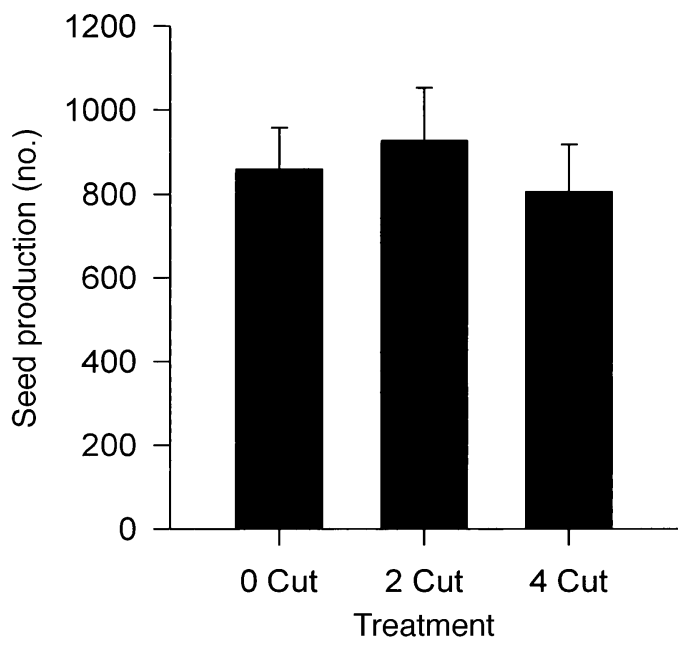

FIG. 1. Effect of the clipping treatments on seed production. There are no significant differences among treatments. Values are means $+95 \%$ confidence intervals.

in the 2-cut and 4-cut treatments were bushier than plants in the 0-cut treatment (Table 2, Fig. 3c). These results indicate that one way that plants compensate for damage by Haplorhynchites is by producing additional inflorescences on higher order branches later in the season.

A second way in which plants compensate for simulated Haplorhynchites damage is by filling more seeds in their remaining heads. ANOVA of the number of seeds produced in heads 3 and 4 finds that more seeds are produced by plants in the 2-cut treatment than by plants in the 0 -cut treatment (Table 3). Similarly, for heads 5 and 6,7 and 8, and 9 and 10, the number of seeds produced by plants in the 4-cut treatment is always greater than the number of seeds produced by plants in the 2-cut treatment, which in turn is always greater than the number of seeds produced in the 0-cut treatment (Table 3). Finally, the number of seeds produced by heads 11 and higher is significantly greater on plants in the 2-cut and 4-cut treatments than on plants in the 0 -cut treatment (Table 3). Although later heads tend to produce fewer viable seeds than early heads (compare row entries in Table 3), plants from which the early heads have been removed are able to produce as many seeds in their earliest remaining heads as plants from which no heads have been removed produce in their earliest heads (e.g., compare entries on the left diagonal in Table 3). Thus, filling more seeds in remaining heads accounts, in part, for the ability of plants to compensate for simulated Haplorhynchites damage.

In addition, later heads are less susceptible to damage by herbivores other than Haplorhynchites than are early heads (compare row entries in Table 4). Thus, while on any given pair of heads plants in the 2-cut and 4cut treatments tend to experience more damage than plants in the 0 -cut treatment because the early suscep- tible heads are missing from clipped plants, overall, fewer seeds are eaten on plants in the 4-cut treatment than on plants in the 0-cut or 2-cut treatments (significant treatment effect in ANOVA: $F_{2,240}=3.54 ; P<$ 0.0306; Table 4). By effectively flowering later, plants in the 4-cut treatment avoid damage by other herbivores, and this response contributes to their ability to compensate for Haplorhynchites damage. Much of this herbivore effect is due to damage by Plagiomimicus (data comparing damage by each herbivore not presented), which eats more seeds on plants in the 0 -cut treatment than on plants in the clipped treatments $\left(F_{2,240}\right.$ $=8.08 ; P<0.0004$; Fig. 4).

Interestingly, although there are no differences among treatments for mean seed size when all seeds are considered (Tables 1 and 5), examination of pairs of heads yields some intriguing effects. Early heads produce larger seeds than later heads (compare row entries in Table 5), and this difference is most striking in the first two heads. However, except for heads 3 and 4 , heads on clipped plants produce somewhat larger seeds than heads on unclipped plants, and it is these differences that lead to no overall difference in seed size among treatments (compare column entries in Table 5). Thus, a fourth mechanism of compensation for Haplorhynchites damage is to marginally increase the size of seeds produced by remaining heads.

Although there is no genetic variation among the families used in this experiment for the ability to compensate for simulated Haplorhynchites damage, these families do differ dramatically in date of first flower (sire effect in ANOVA: $F_{7,377}=8.99 ; P<0.0001$ ),

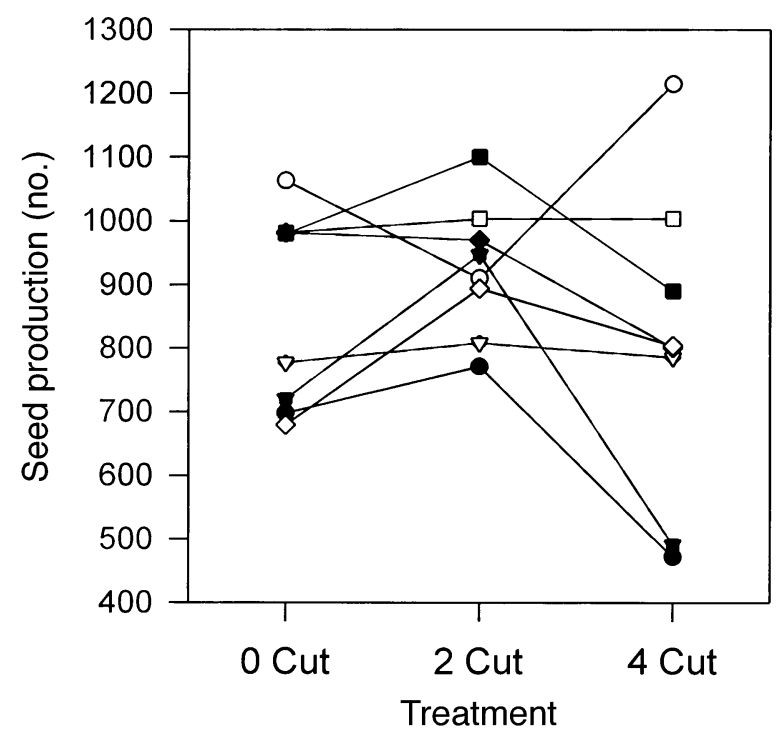

FIG. 2. Effect of the clipping treatments on seed production in each of the eight sires. Each line connects seed production in each of the three treatments for one of the eight sires. Although seed production varies among sires, sires did not respond differently to the clipping treatments. Values are untransformed means. 

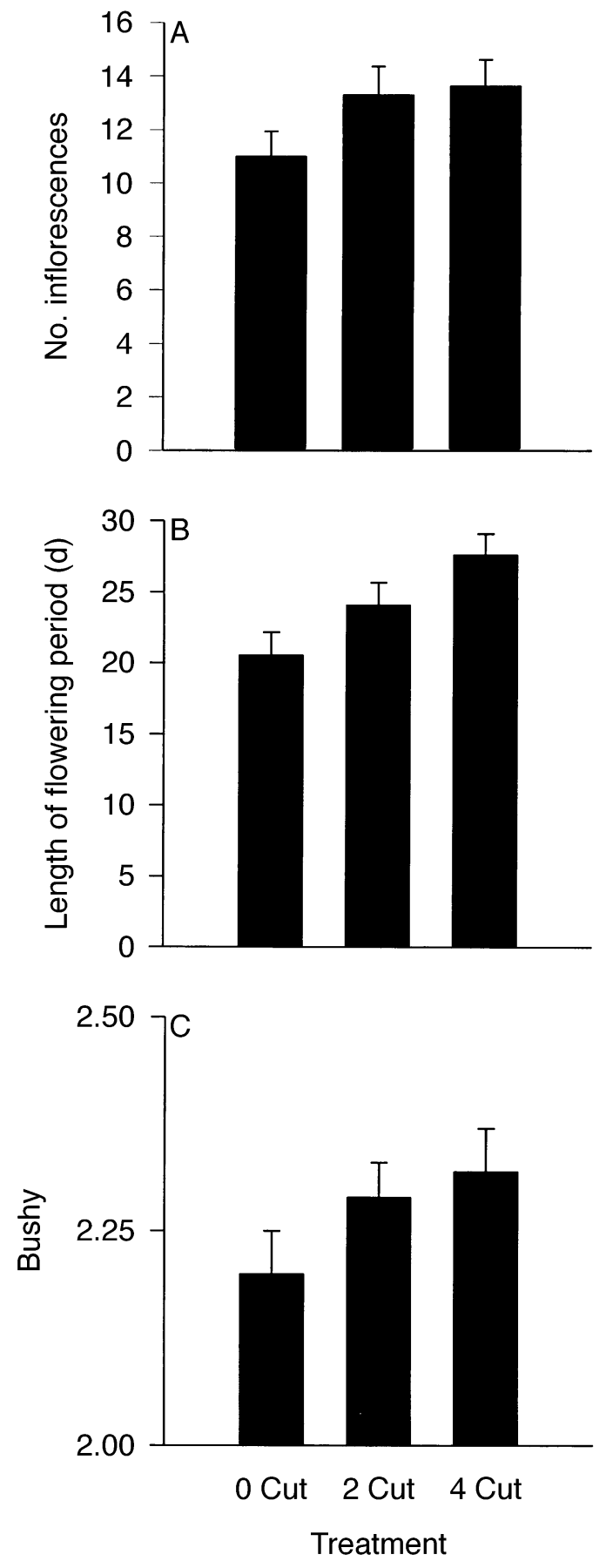

FIG. 3. Effect of the clipping treatments on flowering variables. Values are untransformed means $+95 \%$ confidence intervals. (A) Number of inflorescences. (B) Length of the flowering period in days. (C) Bushy (a metric that indicates the degree to which inflorescences are on higher order branches).

the length of the flowering period, bushiness, and perhaps marginally in number of inflorescences (Table 2); as well as for mean seed size (Table 1). That these families differ in flowering phenology and branching morphology is not surprising since we selected these families for this experiment specifically for that reason. However, it is interesting to note that, despite amongfamily differences in phenology, morphology, and seed size, all families responded to the clipping treatments in the same way (nonsignificant sire $\times$ clipping treatment interactions; Tables 1 and 2). Thus, at least to the extent that these characters allow plants to compensate for damage, all families are using a similar mechanism to effect that compensation.

\section{DISCUSSION}

The results presented here constitute the most detailed available examination of mechanisms of tolerance of herbivore damage. Multiple processes allow Helianthus annuus to compensate for simulated Haplorhynchites damage. Relative to undamaged plants, damaged plants produce additional inflorescences on higher order branches at the end of the flowering period, fill additional seeds in remaining inflorescences, increase seed size in some remaining inflorescences, and (by effectively flowering later) become more resistant to damage by other herbivores. Despite the negative effects of natural Haplorhynchites damage on plant fitness found in other experiments (Pilson 2000a; E. Sundvall and D. Pilson, unpublished manuscript), in this experiment these processes allowed plants to fully compensate for damage.

Moreover, there were no differences among the eight families in their ability to tolerate simulated Haplorhynchites damage. This seems surprising since the families clearly varied in characters that are related to compensatory ability. For example, these families differ in their apparent degree of apical dominance, measured as the proportion of leaf area on branches relative to the main stem. In addition, adding additional inflorescences on higher order meristems, which must, in part, be controlled by changes in apical dominance, contributes to compensatory ability. Despite varying degrees of apical dominance in undamaged plants, all families appear to have altered their apical dominance in the same way (nonsignificant sire $\times$ treatment interaction for bushy; Table 2), which allowed them to similarly compensate for damage.

One possible explanation for our results is that genetic differences in tolerance are only apparent if multiple components of fitness are evaluated simultaneously. To test this idea we performed a multivariate analysis of variance (MANOVA) of seed number and total seed mass. (Because mean seed size was not normally distributed, it could not be included in this analysis.) In this analysis, the sire $\times$ clipping treatment interaction was not significant (Wilk's $\lambda ; P<0.7386$ ), indicating no differences among sires in compensatory ability. Similarly, differences in the compensatory response might only apparent if multiple characters contributing to tolerance are evaluated simultaneously. In a MANOVA of the number of inflorescences, length 
TABLE 3. Mean number of filled seeds produced by indicated heads in each treatment (1 SE in parentheses).

\begin{tabular}{lccccccc}
\hline \hline & \multicolumn{7}{c}{ Number of filled seeds } \\
\cline { 2 - 8 } Treat- & Heads & Heads & Heads & Heads & Heads & Heads 11 & All \\
ment & $1+2$ & $3+4$ & $5+6$ & $7+8$ & $9+10$ & and up & heads \\
\hline 0-Cut & 233.3 & $210.4^{\mathrm{a}}$ & $138.2^{\mathrm{a}}$ & $101.2^{\mathrm{a}}$ & $74.1^{\mathrm{a}}$ & $109.2^{\mathrm{a}}$ & $860.1^{\mathrm{a}}$ \\
& $(12.7)$ & $(12.8)$ & $(10.6)$ & $(9.9)$ & $(8.5)$ & $(17.2)$ & $(49.5)$ \\
2-Cut & $\ldots$ & $266.0^{\mathrm{b}}$ & $213.2^{\mathrm{b}}$ & $145.0^{\mathrm{b}}$ & $100.9^{\mathrm{b}}$ & $205.9^{\mathrm{b}}$ & $919.8^{\mathrm{a}}$ \\
& $\ldots$ & $(12.2)$ & $(12 .)^{\mathrm{a}}$ & $(11.1)$ & $(10.1)$ & $(32.1)$ & $\left(62.5^{2}\right.$ \\
4-Cut & $\ldots$ & $\cdots$ & $244.5^{\mathrm{c}}$ & $182.4^{\mathrm{c}}$ & $141.8^{\mathrm{c}}$ & $242.1^{\mathrm{b}}$ & $774.3^{\mathrm{a}}$ \\
& & & $(12.6)$ & $(11.9)$ & $(11.2)$ & $(32.9)$ & $(54.9)$ \\
\hline
\end{tabular}

Notes: Untransformed means and standard errors are presented; data analyses were performed on transformed variables when necessary to improve normality. Column entries with different superscript letters are significantly different from one another at the $P<0.0166$ level (Bonferroni correction for three comparisons within each ANOVA). $F$ statistics and uncorrected $P$ values for the overall treatment effects in these ANOVAs are $F_{1,153}=10.71, P<0.0013$ for heads 3 and $4 ; F_{2,242}=23.76, P<0.0003$ for heads 5 and $6 ; F_{2,240}=16.04, P<0.0001$ for heads 7 and $8 ; F_{2,240}=13.19, P<0.0001$ for heads 9 and $10 ;$ and $F_{2,240}=7.47, P<0.0007$ for heads 11 and higher. Bonferroni correction for five tests $(0.05 / 5=0.01)$ indicates that across all heads the overall treatment effect is significant as well.

of the flowering period, and bushy, the sire $\times$ clipping treatment interaction was not significant (Wilk's $\lambda ; P$ $<0.2858$ ), indicating that the clipping treatments affected each of the sires in the same way. Thus, simultaneously considering characters contributing to fitness or to the compensatory response does not increase our ability to detect variation among sires in tolerance or mechanisms of tolerance.

Interestingly, comparison of the results presented here with other data suggests that the expression of genetic variation for tolerance varies among environments. For example, in an experiment in which the competitive environment was varied, genetic variation for tolerance was found in the high competition, but not in the low competition, environment (D. Pilson and E. Sundvall, unpublished manuscript). Consistent with this result, the competitive environment in the experiment described here was probably similar to the low competition environment in the Pilson and Sundvall experiment. Characters that contribute to genetic variation in compensatory ability in other environments remain unknown. However, it seems likely that expression of the tolerance characters identified in this experiment also varies among environments, and this leads to variation in compensatory ability in some environments as well. Since the degree of compensation for damage is well known to vary among environments (e.g., Maschinski and Whitham 1989, Hjalten et al. 1993, Trumble et al. 1993, Juenger and Bergelson 1997 , Mabry and Wayne 1997, Huhta et al. 2000a), it is perhaps not surprising that expression of genetic variation for tolerance might vary among environments as well.

The conclusion we have drawn from this experiment, that plants completely compensate for simulated Haplorhynchites damage, assumes that the damage levels we imposed are similar to those experienced by natural

TABLE 4. Mean number of seeds eaten by seven seed- and head-feeding herbivores other than Haplorhynchites in the indicated heads in each treatment (1 SE in parentheses).

\begin{tabular}{lccccccc}
\hline \hline & \multicolumn{7}{c}{ Number of seeds eaten } \\
\cline { 2 - 8 } Treat- & Heads & Heads & Heads & Heads & Heads & Heads 11 & All \\
ment & $1+2$ & $3+4$ & $5+6$ & $7+8$ & $9+10$ & and up & heads \\
\hline 0-Cut & 73.0 & $73.9^{\mathrm{a}}$ & $60.0^{\mathrm{a}}$ & $45.0^{\mathrm{a}}$ & $33.4^{\mathrm{a}}$ & $46.2^{\mathrm{a}}$ & $328.6^{\mathrm{a}}$ \\
& $(4.1)$ & $(5.1)$ & $(4.5)$ & $(4.4)$ & $(4.1)$ & $(7.3)$ & $(18.8)$ \\
2-Cut & $\cdots$ & $80.4^{\mathrm{a}}$ & $65.4^{\mathrm{ab}}$ & $55.2^{\mathrm{b}}$ & $42.0^{\mathrm{b}}$ & $74.0^{\mathrm{b}}$ & $315.7^{\mathrm{a}}$ \\
& $\ldots$ & $(4.5)$ & $(4.7)$ & $(4.7)$ & $(4.2)$ & $(11.1)$ & $(19.9)$ \\
4-Cut & $\ldots$ & $\cdots$ & $71.9^{\mathrm{b}}$ & $61.3^{\mathrm{b}}$ & $44.4^{\mathrm{b}}$ & $85.5^{\mathrm{b}}$ & $261.4^{\mathrm{b}}$ \\
& & & $(4.5)$ & $(4.1)$ & $(3.9)$ & $(10.0)$ & $(15.5)$ \\
\hline
\end{tabular}

Notes: Untransformed means and standard errors are presented; data analyses were performed on transformed variables to improve normality. Column entries with different superscript letters are significantly different from one another at the $P<0.0166$ level (Bonferroni correction for three comparisons). $F$ statistics and uncorrected $P$ values for the overall treatment effects in these ANOVAs are: $F_{1,153}=1.76, P<0.1864$ in heads 3 and $4 ; F_{2.242}=4.78, P<0.0092$ in heads 5 and $6 ; F_{2,240}=8.11, P<0.0004$ in heads 7 and $8, F_{2,240}=5.83, P<0.0034$ in heads 9 and $10 ; F_{2,240}=5.22, P<0.0005$ in heads 11 and higher. Bonferroni correction for five tests $(0.05 / 5=0.01)$ suggests that across all heads the overall treatment effect is significant as well. 


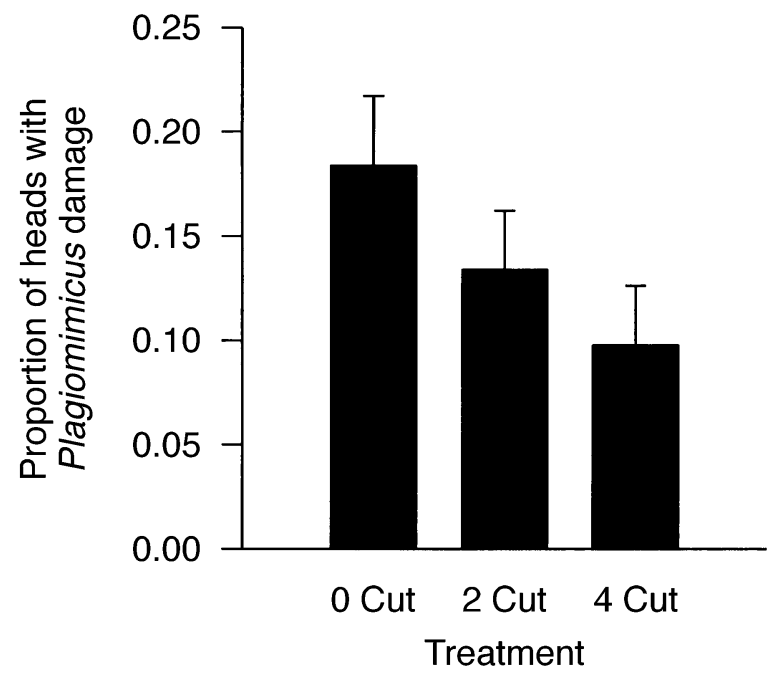

FIG. 4. Proportion of inflorescences with damage by Plagiomimicus spumosum, a head-feeding moth that reduces seed production in infested heads by more than $50 \%$. Values are untransformed means $+95 \%$ confidence intervals.

populations. As noted above, the damage we imposed (removing $\sim 15$ or $\sim 30 \%$ of heads) falls towards the high end of typical damage levels. Thus, our treatments did not impose damage so trivial that the plants would be little affected. Moreover, because $H$. annuus is an annual, reallocation patterns that contribute to tolerance, such as those we observed, cannot decrease fitness in future years, as they might in a perennial species.

In addition, our conclusion of complete compensation depends on the accuracy of our estimate of plant fitness. One limitation of our work is that seed production only estimates the maternal contribution to fitness, and it is possible that Haplorhynchites damage has different effects on fitness gained through male and female function. For example, if clipping generally occurs after pollen dispersal but before seeds mature, then it might be that paternal fitness is increased by clipping (because clipped plants produce more inflorescences), and plants might actually overcompensate for damage. However, clipping generally occurs no later than just following anthesis of an inflorescence's first florets, so pollen dispersal from clipped heads is probably inconsequential. More generally, any compensatory response to damage by a seed-feeding herbivore that involves producing additional inflorescences might, depending on the timing of damage, lead to greater compensation through the paternal, as compared to the maternal, contribution to fitness (e.g., Paige et al. 2001). The effect of herbivory on the maternal and paternal contributions to plant fitness have only rarely been examined, but the data suggest that compensatory responses through male and female function can be either similar (Gronemeyer et al. 1997, Agrawal et al. 1999) or variable (Paige et al. 2001).

Another potential limitation of our estimate of plant fitness is that we have assumed that equal mean seed size among the treatments implies equal compensation. However, as is clear from Table 5, seeds in heads 1 and 2 are an order of magnitude larger, on average, than seeds in the remaining heads, regardless of treatment. No seeds on clipped plants approach the mean size of seeds in heads 1 and 2 on unclipped plants, and if these especially large seeds contribute disproportionately to plant fitness then plants may not fully compensate for damage. While we have no data on the effect of seed size on plant fitness in $H$. annuиs, in other species seed size generally contributes positively to seedling survival and size, and therefore to plant fitness (Fenner 1985).

A third potential limitation of this experiment is that we used artificial, rather than natural, damage to quantify the compensatory response. Plants are well known to respond physiologically to herbivore damage, through induced defenses, for example (Karban and Baldwin 1997), and the absence of herbivore-induced

TABLE 5. Mean seed mass $(\mathrm{g})$ in the indicated heads in each treatment (1 SE in parentheses).

\begin{tabular}{|c|c|c|c|c|c|c|c|c|}
\hline \multirow[b]{2}{*}{$\begin{array}{l}\text { Treat- } \\
\text { ment }\end{array}$} & \multicolumn{7}{|c|}{ Mean seed mass } & \multirow[b]{2}{*}{$\begin{array}{c}\text { Total seed } \\
\text { mass }\end{array}$} \\
\hline & $\begin{array}{l}\text { Heads } \\
1+2\end{array}$ & $\begin{array}{l}\text { Heads } \\
3+4\end{array}$ & $\begin{array}{l}\text { Heads } \\
5+6\end{array}$ & $\begin{array}{l}\text { Heads } \\
7+8\end{array}$ & $\begin{array}{c}\text { Heads } \\
9+10\end{array}$ & $\begin{array}{l}\text { Heads } 11 \\
\text { and up }\end{array}$ & All heads & \\
\hline 0-Cut & $\begin{array}{c}0.0333 \\
(0.0194)\end{array}$ & $\begin{array}{r}0.0079^{\mathrm{a}} \\
(0.0017)\end{array}$ & $\begin{array}{r}0.0058^{a} \\
(0.0002)\end{array}$ & $\begin{array}{r}0.0054^{\mathrm{a}} \\
(0.0002)\end{array}$ & $\begin{array}{r}0.0052^{\mathrm{a}} \\
(0.0003)\end{array}$ & $\begin{array}{r}0.0045^{\mathrm{a}} \\
(0.0002)\end{array}$ & $\begin{array}{r}0.0063^{\mathrm{a}} \\
(0.0003)\end{array}$ & $\begin{array}{r}5.3350^{\mathrm{a}} \\
(0.3126)\end{array}$ \\
\hline 2-Cut & $\ldots$ & $\begin{array}{c}0.0071^{\mathrm{b}} \\
(0.0002)\end{array}$ & $\begin{array}{r}0.0064^{\mathrm{b}} \\
(0.0002)\end{array}$ & $\begin{array}{l}0.0061^{\mathrm{a}} \\
(0.0004)\end{array}$ & $\begin{array}{l}0.0052 \mathrm{a}^{\mathrm{b}} \\
(0.0002)\end{array}$ & $\begin{array}{l}0.0049 \mathrm{a}^{\mathrm{b}} \\
(0.0002)\end{array}$ & $\begin{array}{r}0.0061^{\mathrm{a}} \\
(0.0001)\end{array}$ & $\begin{array}{r}5.8490^{\mathrm{a}} \\
(0.4046)\end{array}$ \\
\hline 4-Cut & $\cdots$ & $\ldots$ & $\begin{array}{r}0.0074^{\mathrm{b}} \\
(0.0009)\end{array}$ & $\begin{array}{r}0.0065^{\mathrm{b}} \\
(0.0002)\end{array}$ & $\begin{array}{r}0.0058^{\mathrm{b}} \\
(0.0003)\end{array}$ & $\begin{array}{r}0.0058^{\mathrm{b}} \\
(0.0002)\end{array}$ & $\begin{array}{r}0.0059^{\mathrm{a}} \\
(0.0001)\end{array}$ & $\begin{array}{r}5.0298^{\mathrm{a}} \\
(0.3626)\end{array}$ \\
\hline
\end{tabular}

Notes: Untransformed means and standard errors are presented. Analyses of all variables except for total seed mass were performed on ranked data because data were severely non-normal. Analysis of total seed mass was performed on transformed data. Column entries with different superscript letters are significantly different from one another at the $P<0.0166$ level (Bonferroni correction for three comparisons). $F$ statistics and uncorrected $P$ values for the overall treatment effects in these ANOVAs are: $F_{1,208}=20.89, P<0.0001$ in heads 3 and $4 ; F_{2,304}=8.63, P<0.0002$ in heads 5 and $6 ; F_{2,25}=11.29, P$ $<0.0001$ in heads 7 and $8, F_{2,214}=2.91, P<0.0564$ in heads 9 and $10 ;$ and $F_{2,162}=3.28, P<0.0401$ in heads 11 and higher. Bonferroni correction for five tests $(0.05 / 5=0.01)$ suggests that across all heads the overall treatment effect is significant as well. 
(rather than the absence of damage-induced) responses could have allowed plants to better compensate for the artificial damage that we imposed. While we have no way of knowing if the absence of specifically herbivore-induced responses might explain our results, we think it is unlikely that they do. The removal of a large photosynthate sink (the inflorescence) provides a major signal to the plant, and additional elicitors would seem unnecessary. In addition, because Haplorhynchites larvae feed on the clipped heads (that fall to the ground) there has presumably been no selection on Haplorhynchites to provide any particular signal to the plant.

A number of studies have found either complete compensation or overcompensation for small to moderate amounts of damage, at least in some environmental conditions (Paige and Whitham 1987, Lennartsson et al. 1998, Huhta et al. 2000b), and it is tempting to speculate about overcompensation for Haplorhynchites damage in the current experiment. Although not significant, seed production in the 2-cut treatment is greater than in the 0-cut treatment (Fig. 1). In addition, seven of the eight families appear to at least maintain fitness in the 2-cut treatment relative to fitness in the 0-cut treatment (Fig. 2). However, the power in this experiment is quite large (there were 128 plants in each of the three treatments), so overcompensation seems quite unlikely. Seed production in $H$. annuиs is very sensitive to microenvironmental variation, and even in relatively uniform experimental conditions there is considerable within treatment and within family variation in seed production (Fig. 1), which apparently contributed to the nonsignificant effect of the clipping treatment on fecundity. In addition, as discussed above, clipped plants produce no especially large seeds, and for this reason fitness in these plants may be overestimated by examination of only seed number and mean seed size.

The next step in understanding constraints on the evolution of response to damage by Haplorhynchites in $H$. annuus will be to more carefully examine patterns of natural selection on characters contributing to both resistance and tolerance, particularly in environments in which resistance and tolerance are genetically variable. Resistance to Haplorhynchites is determined in large part by flowering time, with early flowering plants experiencing greater damage (Pilson 2000a). As reported here, tolerance is controlled by the effect of damage on apical dominance, resource allocation among inflorescences, and apparent flowering phenology. Thus, it is natural selection (and constraints) acting on these characters that will affect the evolution of response to damage. By moving beyond operational definitions of resistance and tolerance we will be better able to elucidate constraints on the evolution of response to herbivory.

\section{ACKNOWLEDGMENTS}

Sara Morgan, Sara Rathe, Matt Paulsen, Nick Pleskac, Lisa Prosterman, and Eric Sundvall helped in the field or counted and weighed seeds. We thank Eric Sundvall for useful discussions. Matt Paulsen helped with insect identification. Isophrictis similiella was determined by David Adamski and Neolasioptera helianthi was determined by Raymond J. Gagne (retired), Research Entomologists at the Systematic Entomology Laboratory of the United States Department of Agriculture. This work was supported by NSF DEB-972607 to D. Pilson and the University of Nebraska Research Council.

\section{Literature Cited}

Agrawal, A. A., S. Y. Strauss, and M. J. Stout. 1999. Costs of induced responses and tolerance to herbivory in male and female fitness components in wild radish. Evolution 53:1093-1104.

Bergelson, J., T. Juenger, and M. J. Crawley. 1996. Regrowth following herbivory in Ipomopsis aggregata: compensation but not overcompensation. American Naturalist 148:744755.

Berglund, D. R. 1994. Sunflower production. North Dakota Agricultural Experiment Station Bulletin 25 (revised). North Dakota State University, Fargo, North Dakota, USA. Charlet, L. D., G. J. Brewer, and V. H. Beregovoy. 1992. Insect fauna of the heads and stems of native sunflowers (Asterales:Asteraceae) in eastern North Dakota. Bulletin of the Entomological Society of America 21:493-500.

Charlet, L. D., G. J. Brewer, and B. A. Franzmann. 1997. Sunflower insects. Pages 183-261 in A. A. Schneiter, editor. Sunflower technology and production. Agronomy monograph number 35. American Society of Agronomy, Crop Science Society of America, and Soil Science Society of America, Madison, Wisconsin, USA.

Crawley, M. J. 1983. Herbivory: the dynamics of animalplant interactions. University of California Press, Berkeley, California, USA.

Crawley, M. J. 1993. On the consequences of being eaten. Evolutionary Ecology 7:124-125.

Dalling, J. W., and K. E. Harms. 1999. Damage tolerance and cotyledonary resource use in the tropical tree Gustavia superba. Oikos 85:257-264.

Doak, D. 1991. The consequences of herbivory for dwarf fireweed: different time scales, different morphological scales. Ecology 72:1397-1407.

Fenner, M. 1985. Seed ecology. Chapman and Hall, New York, New York, USA.

Fineblum, W. L., and M. R. Rausher. 1995. Tradeoff between resistance and tolerance to herbivore damage in a morning glory. Nature 377:517-520.

Foroni, J., and J. Nunez-Farfan. 2000. Evolutionary ecology of Datura stramonium: genetic variation and costs for tolerance to defoliation. Evolution 54:789-797.

Gronemeyer, P. A., B. J. Dilger, J. L. Bouzat, and K. N. Paige. 1997. The effect of herbivory in scarlet gilia: better moms also make better pops. American Naturalist 150:592-602.

Hamilton, R. W. 1973. Observations on the biology of Haplorhynchites aeneus (Boheman) (Coleoptera: Rhynchitidae). Coleopterists Bulletin 27:83-85.

Harnett, D. C., and W. G. Abrahamson. 1979. Effects of stem gall insects on life-history patterns in Solidago canadensis. Ecology 60:910-917.

Heiser, C. B., D. M. Smith, S. B. Clevenger, W. C. Martin. 1969. The North American sunflowers (Helianthus). Memoirs if the Torrey Botanical Club 22:1-218.

Hjalten, J., K. Danell, and L. Ericson. 1993. Effects of simulated herbivory and intraspecific competition on the compensatory ability of birches. Ecology 74:1136-1142.

Hochwender, C. G., R. J. Marquis, and K. A. Stowe. 2000. The potential for and constraints on the evolution of compensatory ability in Asclepias syriaca. Oecologia 122:361370.

Huhta, A.-P., K. Hellstrom, P. Rautio, and J. Tuomi. $2000 a$. A test of the compensatory continuum: fertilization in- 
creases and below-ground competition decreases the grazing tolerance of tall wormseed mustard (Erysimum strictum). Evolutionary Ecology 14:353-372.

Huhta, A.-P., T. Lennartsson, J. Tuomi, P. Rautio, and K. Laine. 2000b. Tolerance of Gentianella campestris in relation to damage intensity: an interplay between apical dominance and herbivory. Evolutionary Ecology 14:373392.

Juenger, T., and J. Bergelson. 1997. Pollen and resource limitation of compensation to herbivory in scarlet gilia, Ipomopsis aggregata. Ecology 78:1684-1695.

Juenger, T., and J. Bergelson. 2000. The evolution of compensation to herbivory in scarlet gilia, Ipomopsis aggregata: herbivore imposed natural selection and the quantitative genetics of tolerance. Evolution 54:764-777.

Karban, R., and I. T. Baldwin. 1997. Induced responses to herbivory. University of Chicago Press, Chicago, Illinois, USA.

Kotanen, P. M., and J. P. Rosenthal. 2000. Tolerating herbivory: does the plant care if the herbivore has a backbone? Evolutionary Ecology 14:537-549.

Kreitner, G., and C. E. Rogers. 1981. Sunflower seed midge: effects of larval infestation on pericarp development in sunflower. Annals of the Entomological Society of America 74:431-435.

Lennartsson, T., P. Nilsson, and J. Tuomi. 1998. Induction of overcompensation in the field gentian, Gentianella campestris. Ecology 79:1061-1072.

Mabry, C. M., and P. W. Wayne. 1997. Defoliation of the annual herb Abutilon theophrasti: mechanisms underlying reproductive compensation. Oecologia 111:225-232.

Marquis, R. J. 1988. Phenological variation in the neotropical understory shrub Piper arieianum-causes and consequences. Ecology 69:1552-1565.

Marquis, R. J. 1992. The selective impact of herbivores. Pages 301-325 in R. S. Fritz and E. L. Simms, editors. Plant resistance to herbivores and pathogens: ecology, evolution, and genetics. University of Chicago Press, Chicago, Illinois, USA.

Maschinski, J., and T. G. Whitham. 1989. The continuum of plant responses to herbivory: the influence of plant association, nutrient availability, and timing. American Naturalist 134:1-19.

Mauricio, R., M. D. Rausher, and D. S. Burdick. 1997. Variation in the defense strategies of plants: are resistance and tolerance mutually exclusive? Ecology 78:1301-1311.

Meyer, G. A. 1998. Pattern of defoliation and its effect on growth and photosynthesis of goldenrod. Functional Ecology 12:270-279.

Paige, K. N., and T. G. Whitham. 1987. Overcompensation in response to mammalian herbivory: the advantage of being eaten. American Naturalist 129:407-416.

Paige, K. N., B. Williams, and T. Hickox. 2001. Overcompensation through the paternal component of fitness in Ipomopsis arizonica. Oecologia 128:72-76.

Pilson, D. 2000a. Herbivory and natural selection on flowering phenology in wild sunflower, Helianthus annuus. Oecologia 122:72-82.

Pilson, D. 2000b. The evolution of plant response to herbivory: simultaneously considering resistance and tolerance in Brassica rapa. Evolutionary Ecology 14:457-489.

Prins, A. H., and H. J. Verkaar. 1989. Responses of Cynogolssum officinale and Senecio jacobaea to various degrees of defoliation. New Phytologist 111:725-731.

Rogers, C. E. 1988. Insects from native and cultivated sunflowers (Helianthus) in southern latitudes of the United States. Journal of Agricultural Entomology 5:267-287.

Rogers, C. E., W. D. Perkins, and G. J. Seiler. 1986. Bionomics of Stibadium spumosum (Lepidoptera: Noctuidae), a pest of sunflower in the southern plains. Environmental Entomology 15:1275-1278.

SAS. 1990. SAS/STAT User's Guide, Version 6. Fourth edition. SAS Institute, Cary, North Carolina, USA.

Simms, E. L., and J. Triplett. 1994. Costs and benefits of plant responses to disease: resistance and tolerance. Evolution 48:1973-1985.

Stowe, K. A., R. J. Marquis, C. G. Hochwender, and E. L. Simms. 2000. The evolutionary ecology of tolerance to consumer damage. Annual Review of Ecology and Systematics 31:565-595.

Strauss, S. Y., and A. A. Agrawal. 1999. The ecology and evolution of plant tolerance to herbivory. Trends in Ecology and Evolution 14:179-185.

Tiffin, P. 2000. Mechanisms of tolerance to herbivore damage: what do we know? Evolutionary Ecology 14:523-536.

Tiffin, P., and M. D. Rausher. 1999. Genetic constraints and selection acting on tolerance to herbivory in the common morning glory Ipomoea purpurea. American Naturalist 154:700-716.

Trumble, J. T., D. M. Kolodny-Hirsch, and I. P. Ting. 1993. Plant compensation for arthropod herbivory. Annual Review of Entomology 38:93-119.

Tuomi, J., P. Nilsson, and M. Astrom. 1994. Plant compensatory responses: bud dormancy as an adaptation to herbivory. Ecology 75:1429-1436.

Underhill, E. W., E. E. Rogers, and L. R. Hogge. 1987. Sex attractants for two sunflower pests, Eucosma womonana (Lepidoptera: Tortricidae) and Isophrictis similiella (Lepidoptera: Gelechiidae). Environmental Entomology 16: 463-466.

van der Meijden, E., M. Wijn, and H. J. Verkaar. 1988. Defense and regrowth, alternative plant strategies in the struggle against herbivores. Oikos 51:355-363. 